\title{
DROPPING OUT OF SCHOOL
}

\author{
M. Teneva* \\ Faculty of Education, Trakia University, Stara Zagora, Bulgaria
}

\begin{abstract}
The modern technological society needs educated people who, through their high professionalism, are called upon to create its progress. In this aspect, a serious problem stands out - the dropout from school of a large number of children, adolescents and young people. The object of the research is the premature interruption of training for a large number of Bulgarian students. The subject of the study is the causes that provoke the students' dropping out of school. The aim is to differentiate the negative factors leading to dropping out of school, and to identify the motivating factors that encourage the individual to return to the educational environment. In order to realize the so set target, a specially designed test-questionnaire has been used. The survey was conducted among students attending evening courses who have left their education for various reasons and are currently back to the school institution. The contingent of the study includes 120 students from the evening schools. The results indicate that the reasons which prompted the students to leave school early differentiate into four groups: family, social, economic, educational, personal. The motivation to return to school has been dictated in the highest degree by the need for realization of the person on the labor market, followed by the possibility for full social functioning.
\end{abstract}

Key words: education; school; reasons for dropping out of school

\section{INTRODUCTION}

Bulgaria is among the countries that have sustainable traditions in education.

The retrospective glance over time reveals the fact according to which from the adoption of Christianity and the Slavic alphabet in the second half of the IXth century, arise the first Bulgarian schools.

Knyaz Boris I gave meaning to the idea of the emergence and development of education in Bulgaria. Education of the nation is seen as a factor that can provide new horizons for development and prosperity of the country to contribute to its recognition by other European countries.

After the liberation of Bulgaria from the Ottoman Rule in 1878 , the beginning of mass spread of education was initiated. Bulgarian educational system is regulated by legislation according to which schools in Bulgaria are defined as schools of the people and the teaching in primary schools is compulsory and free (1)

\footnotetext{
*Correspondence to: Maria Teneva, Faculty of Education, Trakia University - Stara Zagora, Bulgaria,m.s.teneva@abv.bg
}

At present, the Law on pre-school and school education, Article 6, states that education in state and municipal schools is free. Article 8 stipulates that school education is compulsory until the age of 16 (2).

At the background of these traditions and positive trends in the development of education in our country, the data for a large number of students who leave the early educational system sounds alarming.

\section{METHODOLOGY}

In order to differentiate the factors that provoke the person to interrupt their education and to highlight the motivating factors that contribute to the return to the school, a special questionnaire was developed and tested.

The study included students who are studying in evening schools.

To provoke the respondents into confidence in formulating their answers, the test was given to be filled in anonymously. The surveyed persons were required to indicate their sex and chronological age in years.

When processing the obtained data, a percentage analysis was used and scaling ranking. 
DROPPING OUT OF SCHOOL - A PROBLEM OF BULGARIEN SOCIETY

The National Statistical Institute of Bulgaria (NSI) published data according to which in the last 10 years between 250 and 300000 Bulgarians up to 17 years of age have left the educational system.

The reasons for dropping out of school are different. They can be generally differentiated as: family, socio-economic, educational.

The largest number of the dropouts is for family reasons. These are 6.5 thousands students representing a share of $47.9 \%$ of all drop-outs.

The second in rank are the school-leavers due to their desire to go abroad. This is $35.2 \%$ of the dropouts.

At the third place were the drop-outs because of an unwillingness to learn. They represent a share of $10.7 \%$ of school dropouts (3).

These statistics indicate that every year thousands of students leave the educational system and most of them never returned to it.

There is a commitment of the management bodies of the educational system towards overcoming the so differentiated negative trend.

The Ministry of Education and Science provides an opportunity for all public schools to take advantage of the possibilities of Project BG RO 051 001-4.2.05-0001 "Let's make school attractive for young people", "A School of self-affirmation and training to European horizons" (SUCCESS)".

In determining the specific objectives of the Project along with increasing the motivation of students to participate in the educational process, formation of additional knowledge, skills and competencies in students, as well as rationalization of leisure time, it is stated that "the number of early dropouts from education should be limited" (4).

Towards the prevention of dropping out of school a National Program has been developed called "To school without absences" which is aimed at increasing the efficiency of the Bulgarian school by optimizing its internal structure and implementation of the policy to keep children in the educational space.

The specific objective of this National program is aimed at "Development of measures to prevent dropping out of the educational system of students and to reintegrate school dropouts" (5).

Despite the existing regulations, administrative documents, initiatives and activities to improve the quality of education and retention of children in school, still the result in this direction is not satisfactory and every year a large number of students drop out of the Bulgarian school.

\section{RESULTS}

The survey was conducted among students in evening courses that have dropped out from school for various reasons, and are currently back to the school institution.

The results indicate that the reasons which prompted students to leave school early are differentiated into four groups: family, socioeconomic, educational, personal.

The motivation to return to school is dictated in the highest degree by the need for realization of the personal on the labor market, followed by the possibility of full social functioning.

The study involved 120 students. Of these, $53 \%$ are representatives of the female and $47 \%$ are representatives of the male gender.

The age of $24 \%$ of the tested people is in the range between $18-22$ years old, $42 \%$ between the ages of 23-27 years, $26 \%$ were aged 28-32 years and at $8 \%$ the age is greater than 32 years.

The received data indicate that in the first years after coming of age, the young person who has prematurely interrupted his or her education, attempts to achieve realization on the labor market which, because of his or her low education and skills, are unsatisfactory. This to a high extent acts as a motivating factor to return to the educational space. We can assume that it is this fact that is decisive, the highest percentage of the surveyed students are between the ages of 23-27 years.

We focused our research attention to students in the evening schools, because our goal was to differentiate the reasons for dropping out of school, but also to highlight the motivating factors that provoke the young person to return to the educational environment.

The respondents were required to indicate the reasons that prompted them to leave school.

As a result, the survey found that the largest number of students drop out of school for 
family reasons. They represent a share of $48 \%$ of the surveyed persons.

These family reasons, stated by the students, are of a very wide range: raising the child in an incomplete family, migration of a the family, separation of parents, family abuse, neglect of parental duties, underestimation on the part of the family of the role of education for the personal development and fulfillment of children, tolerance on the part of the parents of early marriages and early childbirth in some ethnic groups.

Second place in the ranking scale is occupied by socio-economic reasons.

This group is differentiated as cause by $28 \%$ of the students. They highlight the social and financial problems of the family as a reason for discontinuation of their education: poor living conditions in the home, lack of funds for the purchase of books, textbooks, clothes and shoes for school, the need for children to start an employment in order to contribute financially to the family.

Third in the scale ranks among the causes that provoke school dropout respondents placed the educational reasons. They occupy a share of $16 \%$.

As such, the students pointed out the following: the negative attitude of the school and some of the teachers, failure in individual subjects, low motivation of certain teachers to interact with students, teachers' realization of an inefficient educational process in class.

The fourth position in the ranking scale is taken by personal reasons. They are differentiated by $8 \%$ of the surveyed persons. As key reasons for leaving school, these students indicate the rejection of the group of classmates, uncertainty in their own powers and abilities to tackle challenges in the educational space, low level of personal motivation to visit the school, depression coming from the feeling that you are different from the others.

From the specifics of the presented data it can be concluded that the complex of family and socio-economic reasons occupy a share of $76 \%$ of all the differentiated reasons. Their overcoming stands in a sense in "the periphery" of the priorities and competencies of the educational institutions.

Towards the overcoming of the educational reasons for dropping out of the Bulgarian school significant work is being done toward changing the educational paradigm.
In this respect, it is worth that practising teachers evaluate the ideas for an educational process directed towards the person, for the subject-subjective interaction with the students in the learning process of transition from an information to a transformation type of training, for shifting from a traditional to an interactive educational model. It is necessary to reorient the purposeful activity of the educator towards breaking the stereotyping, problematizing and individualization of learning, stimulating the creativity and initiative of the students. To realize this type of training, it is needed to reorient the position of the students from a passive to an active coplayer of the teacher in the classroom. By eliminating the boredom in class and making the school a desirable place for children, adolescents and young people, the aim is to help reduce the number of dropouts from school.

We required the respondents to differentiate positive and negative features of the school institution.

Identification of these characteristics of the learners themselves would assist the educators to search strategies to increase the effectiveness of their work and the school institution as a whole.

From the specifics of the answers we find that the differentiated positive features of the school are separated into four groups.

According to the respondents, the most important positive feature of the school correlates to its educational function.

$34 \%$ of the surveyed students appreciate the opportunity at school to accumulate new knowledge, skills and competencies under the guidance of competent educators.

This group of students comprehends the concept of the utility of knowledge and discovers its relationship with the professional and social realization of the personality. Their position is influenced to some extent by the fact that they study in evening schools. Dropping out of the educational system, facing the socio-economic reality, the person experiences a catharsis, conveying a new meaning to the importance of the educational institution and its role in preparing the young generation for the full social and occupational functioning.

A positive feature of the school, second in the ranks scale, is the displayed opportunity for personal interaction with a group of peers. 
Such a response is indicated by $28 \%$ of the surveyed persons. In the first years of its existence, the child is heavily dependent on the care of their parents and the first skills for interpersonal interaction, which is absorbed namely with the group of adults. At a later stage are formed and developed the skills to interact with peers. After the tenth year of the child (6), the peers start to be seen as an authority that during the teenage years often displace the families from their leading position in this regard. For expression of the self, the student needs recognition not only from the group of adults but also from the group of peers. In this respect, the school creates a favorable environment for building self-confidence and personality among the authorities - on the one hand, the classmates (authoritative peers), on the other hand, the teachers (authoritative adults).

This determines the nature of the differentiated as third in the ranks scale - the positive feature of the school. As such, respondents indicated the possibility of interaction with the teachers. Such a trend was observed in the answers of $22 \%$ of the surveyed students.

We stress the fact that students who have dropped out of school have a positive attitude towards the school institution and highlight the personality of the teacher as authoritative. This finding correlates with the reasons put forward by the students themselves for dropping out of school which to the highest level (76\%) are family and socioeconomic and only $16 \%$ are educational.

The possibility to freely design the responses suggests further clarification on the part of the respondents.

As positive characteristics of the individual of the teachers, the respondents indicate their professional competence, humanity, the big complex of roles implemented in the educational space, the supportive environment that is created for education, training and development of students.

As positive characteristics of school, the surveyed persons indicate the acquisition of systematized knowledge, a sense of personal commitment and utility that is created among students through training in school. Such a response is indicated by $16 \%$ of the respondents.

The staying in an educational environment gives a peculiar meaning to the existence of the personality and models in a peculiar way his or her self-esteem. In many cases, the liberal style of upbringing within the family, the complete disinterest of the parents or the neglect of parental responsibilities contribute to a mental confusion, and lead to a substantial inferiority complex in which children, adolescents and young people become entrapped. Many of the surveyed students of the evening schools say they behaved and functioned exactly in this type of families.

In their answers they point out that it is in the school that their "I" has been recognized, there they felt respected and personally engaged in something useful.

In the responses if two percent of the respondents it is stated that staying in school for them was the only opportunity to be in "peace with themselves" and to feel accepted in the social community.

Along with the positive characteristics of the school, the respondents were required to differentiate its negative attributes, as well.

The specifics of the answers established that $30 \%$ of the surveyed people generally like the school and find it difficult to differentiate its negative attributes.

In the answers of $24 \%$ of the respondents it is indicated that among the negative characteristics of the school could be distinguished the disinterest of some teachers to the students and the learning process and ineffective execution of their professional duties.

$20 \%$ indicate that one negative feature of the school is the poor discipline of the students that could be seen in correlation and as a consequence of the previous differentiated negative characteristic. The disciplinary order is one of the factors that determine the effective running of the learning process. It is directly dependent on the ability of the teacher to motivate students for the upcoming academic activities, to break stereotyping, to saturate every part of the lesson with various activities, to realize subject-subjective interaction with the students in the educational process.

When the teacher does not know how to make an optimal use of time and to realize an effective didactic technology, some of the students get bored and get carried away in the event of disruptive behavior.

Regarding the ability to manage the process of training on the part of teachers, Clark stated the following, "I am ready to predict that $90 \%$ of the behavioral problems in class occur at times when the teacher is not teaching. This is 
the time when students start to get bored and take the opportunity to do stupid things" (7)

For $4 \%$ of the surveyed students what repels them from the school and prompted them to suspend their studies is the failure in some subjects. Respondents argue that the educational content in junior and high school education is of high volume and high complexity and the students in the mainstream schools cannot master it successfully.

The responses of $6 \%$ of the respondents indicated that one negative feature of the school is the expression of the subjectivity of some teachers in the assessment of knowledge, skills and competencies of the students.

Subjectivity in applying the estimation system leads to differences in the actual level of knowledge and their assessment set by different teachers.

P. Radev argues that "subjectivity can also occur from the ambiguity in the regulations and their absence which can be used to deliberate its admission" (8).

Evaluation in Bulgarian schools is regulated by Decree N 3 of 15 April 2003 on the assessment system. Since 2000 , state educational standards have been implemented which are decomposed in the curriculum and serve as the main parameter when creating textbooks for students. This implies clearly defined normative documents regulating the assessment in Bulgarian schools. Another question is how they serve the docimological function of the teacher? Do they provide the necessary clarity on how and what the teacher should measure in the learning process?

In terms of objective evaluation, we can emphasize the fact that the mastery of the teacher of the evaluation techniques is in close relation with his or her didactic knowledge but has its relative self-reliance, as well.

$6 \%$ of the respondents pointed as a negative feature of the school the early start of classes in the morning. They point out that for them it was difficult getting up early in the morning, especially when for financial reasons they were forced by their parents to work in order to support the upkeep of the family. Skipping classes of students leads to difficulties in learning the school matter, failure to master the content and very often is factor for dropping out of school.

We asked the students covered by the study to differentiate the reasons which prompted them to return to school.
The largest number of the respondents point out as the most significant reason for returning to school the obtaining of a diploma.

This is mentioned in the answers of up to $68 \%$ of the surveyed students. Indicative is the fact that this group of students is seeking to obtain a diploma as an end in itself. A correlation between the level of education and level of knowledge, skills and competencies of individuals has not been sought. The diploma is not perceived by them as a testimonial to the competence of the candidate in the selection of work, a projection on the self-improvement and self-realization of the personality has not been looked for.

Only $16 \%$ of the respondents point as a reason for returning to school the possibility of a better career. This group of young people interrupting their education, faced with the realities of the labor market, reconsidered the importance of this - to be educated. They found a positive correlation between education and professional development.

In $10 \%$ of the respondents the reasons for returning to school are personal. This group of students is guided in making that, defined by them as a significant, decision by the pursuit of self-esteem. They rationalize the idea that any self-respecting person should make purposeful efforts for their education. Through training they put in front of their own "I" the requirement for self-improvement and selfactualization. This group of students differentiated a pursuit of continuing education in university.

The responses of $6 \%$ of the respondents indicated that their return to school was prompted by a desire for social functioning outside the family environment. This reason is differentiated by representatives of females who left school because of entering into early marriage and childbirth. They operate closed in the family and community and experience a deficit of social interaction with peers and adults outside the family.

Highlighting this reason for returning to school is positively correlated with the stated out merits of the school, in terms of feasibility of interaction with peers and teachers.

\section{CONCLUSION}

The conduced survey gives us ground to differentiate the following conclusions:

Dropping out of school was provoked to the highest degree by family and socio-economic reasons. 
Students, who chose an evening form of training experience respect and esteem for the institution of the school, appreciate its educational and social role in the development and realization of the personality.

Educational reasons for dropping out of school can be found in the complex content, which is offered to students, in the personal and professional activities of the teacher - his or her attitude to the profession, the organization of interaction with students, his competence in evaluation the students' knowledge.

Young people go back to school led to the highest degree by the motivation to get a diploma, albeit not always its correlation with the ability to achieve better professional and personal fulfillment can be found.

\section{REFERENCES}

1. Atanasov, G. and others. History of Pedagogy and Bulgarian education. Sofia, Veda Slovenia - ZHD. pp. 198-270, 2006
2. Law on pre-school and school education. Sofia, State Gazette. No.79, 2015

3. NSI - Education in the Republic of Bulgaria 2014. Retrieved from http://www.nsi.bg/content/12473 · p.17 (20.02.2017)

4. Instructions for performing work on the project SUCCESS. Retrieved from http://uspeh.mon.bg/docs .p.2 (20.02.2017)

5. National program "To school without absences". $\quad$ Retrieved from https://www.mon.bg/?h=downloadFile\&file $\mathrm{Id}=5675$. p.2 (20.02.2017)

6. Teneva, M. Self-assessment in training 1- 4 class, Stara Zagora, Publisher: Trakia University. p.110, 2012

7. Clark, R. End of boredom in class. Sofia. Publishing house "East-West ". pp.242-243, 2013

8. Radev, Pl. General school didactics. Plovdiv, Plovdiv University Press. p.459, 2005 